\title{
O Papel dos Anticorpos Antifosfolípides nos Acidentes Vasculares Cerebrais
}

\author{
Timone G. * Scaff $M .^{\star \star}$
}

\section{RESUMO}

Os anticorpos antifosfolipides, um grupo heterogêneo de imunogiobulinas que incluem o anticoagulante lúpico e anticardiolipina, através de sua interaçāo com complexos proteicos fosfolípides, podem estar associados a eventos trombóticos de repetiçāo (tanto arteriais como venosos). Podem ser observadas oclusōes vasculares em todos os órgãos inclusive o cérebro. Estima-se que cerca de $20 \%$ da população com Apls positivo, possuam apresentar infartos cerebrais. Geralmente são pacientes jovens, que permaneceram com sequelas importantes. Em um estudo realizado no HCFMUSP, observou-se a presença dos Apls em $11,8 \%$ dos pacientes jovens com AVCl. Este artigo descreve a importåncia da pesquisa dos Apls na investigação laboratorial quanto a etiologia dos AVCls principalmente nos pacientes jovens.

\section{UNITERMOS}

Acidente Vascular Cerebral Insquêmico, anticorpos antifosfolipedes, trombose, coagulação.
- Médico Assistente do Serviço de Emergéncia Neurológica da Divisāo de Clínica Neurológica do HCFMUSP.

** Professor Titular de Neurologia Clínica da FMUSP.

Endereço para correspondência: Divisão de Clínica Neurológica do Hospital dad Clinicas da FMUSP. Rua Dr Enéas Carvalho de Aguiar 255, $5^{2}$ andar, ICHC.
Entre as principais e mais frequientes causas de Acidente Vascular Cerebral Inquêmico (AVCI) podemos citar as etiologias aterotrombóticas e embólicas (cardiogênicas e artério-arteriais). Os infartos lacunares, por sua vez, representam apenas cerca de $15 \%$ dos infartos cerebrais ${ }^{8}$. Alterações hematológicas primárias, também podem estar associadas a eventos isquêmicos, embora em frequência ainda menor. Estima-se que 1 a $4 \%$ dos casos dos AVCI sejam causados por alterações como deficiência hereditária de inibidores da coagulação, alterações plaquetárias, síndrome dos anticorpos antifosfilípides e policitemia vera ${ }^{9}$. Apesar de sua pequena incidência na população, a investigação destas patologias é muito importante principalmente nos pacientes mais jovens, pela sua maior frequência relativa como fator etiológico dos AVCIs neste segmento etário.

Alterações da hemostasia também fora descritas em pacientes com neoplasias, usuárias de contraceptivo oral e gestantes. Nestes casos ocorreria uma predisposição a fenômenos trombóticos, inclusive cerebrais, configurando um estado pré-trombótico ou hipercoagulabilidade ${ }^{8}$.

Outros estudos observaram disfunções dos mecanismos de hemostasia na fase aguda, em muitos pacientes com AVCIs aterotrombóticos e alguns lacunares. Estes pacientes apresentavam um aumento da atividade da trombina, associada ou não a alterações da fibrinólise e da função plaquetária. Através da ação da trombina, moléculas insolúveis de fibrina são formadas a partir de seu precursor, o fibrinogênio ${ }^{11}$. Tanto a fibrina como seu precursor são componentes importantes no tamponamento de um vaso lesado. Estes achados são de grande importância, devido a sua implicação terapêutica, mas não serão discutidos no presente estudo.

\section{DISTÚRBIOS DOS MECANISMOS HEMOSTÁTICOS E TROMBOSE}

Para que ocorra uma hemostasia adequada faz-se necessária uma interação entre vários componentes do sangue: plaquetas, fatores da coagulação e seus inibidores, fatores do sistema fibrinolítico e do endotélio vascular.

As plaquetas são recrutadas pela exposiçao do material do subendotélio, logo após a injúria vascular. Fatores como o fibrinogênio, proteínas adesivas 
como o fator von Willebrand e receptores específicos da membrana das plaquetas seriam necessários na formação do trombo, pois funcionam como pontes intercelulares promovendo a agregação das plaquetas assim como sua ligação com as células do endotélio. A ativação das plaquetas seria limitada pela secreção de fatores inibidores plaquetários como a prostaglandina $I_{2}$ pelo endotélio local ${ }^{p 1}$. A coagulação sanguínea, através de seus 2 sistemas de ativação (via intrínseca e extrínseca), promoveria a síntese da fibrina, importante na estabilização do agregado plaquetário. A trombina, por sua vez, ativa a agregação das plaquetas, e simultaneamente, o maior sistema anticoagulante natural formado pela proteína $\mathrm{C}$ e seus cofatores: proteína $\mathrm{S}$ e a trombomodulina. Isto permitiria uma automodulação das reações da coagulação.

A antitrombina III também representa um inibidor muito importante dos fatores da coagulação.

Através de mecanismos fibrinolíticos fisiológicos, a plasmina age sobre a fibrina, evitando a progressão de um trombo.

Portanto, a presença de uma disfunção em uma destas reações poderia favorecer a ocorrência de eventos trombóti$\cos$.

Alterações da Concentração do Fibrinogênio e do fator VII, por exemplo, representam fatores de risco tão potentes quanto o colesterol para a oclusão arterial ${ }^{11}$.

Outras patologias, como as trombofilias congênitas também estão associadas a um maior risco trombótico: deficiência das proteínas $\mathrm{C}$ e $\mathrm{S}$ e Antitrombina III; síndrome dos anticorpos antifosfolípides e anemia falciforme. Doenças mieloproliferativas como a policitemia rubra vera associada ou não a um aumento da agregação plaquetária também podem contribuir para uma tendência trombótica.

Esta revisão, concentrar-se-à no estudo da síndrome dos anticorpos antifosfolípides, que vem despertando interesse crescente nos últimos anos.

\section{SINDROME DOS ANTICORPOS ANTIFOSFOLIPIDES}

Os Anticorpos Antifosfolípides (Apls) constituem um grupo heterogêneo de imunoglobulinas e incluem o anticoagulante lúpico e a anticardiolipina. $\mathrm{O}$ anticoagulante lúpico foi descrito pela primeira vez em 1952, em pacientes com LES ${ }^{5}$.

Desde então, tem se observado crescente interesse no papel desta família de imunoglobulinas, na ocorrência de eventos trombóticos de repetição. Estes fenômenos trombóticos afetam qualquer orgão, sendo que em cerca de $20 \%$ dos casos podem acometer a circulação cerebral (AVCs e episódios isquêmicos transitórios - EIT) ${ }^{l}$. Portanto, a pesquisa dos Apls deve fazer parte da investigação laboratorial em pacientes com AVCs.
Os anticorpos anticardiolipina (ACL) podem ser detectados através de testes imunoenzimáticos (IgM, IgG e IgA). A presença do anticoagulante lúpico ( $\mathrm{AL}$ ) pode ser suspeitada pelo prolongamento do tempo de tromboplastina ativada. A seguir, é necessário realizar testes mais sensíveis como tempo de recalcificação de plasma ativado com caulim, tempo de protrombina com tromboplastina diluída e a reação com o veneno da víbora Russel ${ }^{15}$. Devido a sua resposta nas reações "in vitro" é que o termo anticoagulante lúpico continua sendo usado, apesar da sua associação clínica maior com fenômenos trombóticos do que com fenômenos hemorrágicos.

$\mathrm{O} A L$ inibe a interação de fatores da coagulação e fosfolipídios, mais particularmente contra a fração fosfolipídica do complexo ativador da protrombina ou protrombinase (fator $\mathrm{Xa}$, fator $\mathrm{V}$, cálcio e fosfolipídios), interferindo na conversão da protrombina em trombina. Parece que estes anticorpos agem também sobre os fosfolipídios das plaquetas interferindo, assim, na produção de prostaciclina. Podem atuar na agregabilidade plaquetária pelo aumento de liberação do cofator de adesividade plaquetária, o fator von Willebrand. Estes fenômenos explicariam a tendência paradoxal a tromboses venosas e arteriais ${ }^{15}$.

O papel doa Apls parece depender da sua afinidade com os vários complexos proteicos fosfolipídicos. Fosfolípides carregados negativamente, expostos durante a ativaçao plaquetária, seriam necessários para a ativação de mecanismos anticoagulantes evolvendo as proteínas $\mathrm{C}$ e $\mathrm{S}$ e a trombomodulina. Estes anticorpos podem interferir na função da proteína $C$ ativada e através de sua interação com a trombomodulina, podem interferir na função do complexo proteína C-S. Observou-se também uma interferência nos mecanismos fibrinolíticos, ativação de complemento, ligação da proteína anticoagulante placentária e uma ação sobre a antitrimbinaIII ${ }^{7}$.

Alguns autores acreditam que os Apls podem resultar mais da exposição de neoantígenos do que de uma desregulação do sistema imunológico. Lesões endoteliais persistentes ou a ativação plaquetária podem causar a exposição de alguns fosfolípedes carregados negativamente originando um estado prétrombótico ${ }^{4}$.

Os Apls podem ocorrer associados ou não a LES e outras doenças autoimunes como artrite reumatóide, arterite temporal, doenças de Behçet, doenças de pele, especialmente livedo reticularis, Sjoegren e doença mista do tecido conectivo.

Testes positivos transitórios, especialmente para ACL, podem ocorrer na ausência dos já citados aspectos clínicos da síndrome dos Apls, depois de episódios infecciosos agudos e também em processos crônicos infecciosos como sífilis, malária e na síndrome de imunodeficiência humana adquirida ${ }^{8}$.

Aparentemente a presença dos Apls pode ser induzida por drogas como fenotiazidas, especialmente clorpromazina, hidralazina, fenitoína e alguns outros compostos. 
Injúrias tissulares podem desencadear o desenvolvimento de anticorpos anticardiolipina após infartos agudos do miocárdio, assim como em pacientes revascularizados.

Denomina-se síndrome primária dos Anticorpos antifosfolípides, a tríade clássica de trombose sistêmica, incluindo a cerebral, Apls e aborto, na ausência de doença autoimune. Outras manifestações, entretanto, tem sido descritas associadas a presença dos Apls: trombocitopenia e anemia hemolítica autoimune; alterações neurológicas não relacionadas à trombose (mielopatias, Guillain-Barré, convulsões, coréia e psicose); alterações cutâneas como livedo reticularis; alterações valvulares de câmara esquerda; hipertensão pulmonar. Distúrbios visuais são sintomas particularmente freqüentes nestes pacientes, com Apls (alterações isquêmicas retinianas, "amaurosis fugax", sintomas visuais relacionados ou não a enxaqueca).

A síndrome de Sneddon caracterizada pela associação de AVC e livedo reticularis representa uma das síndromes associada a presença de Apls. A biópsia de pele nestes casos evidencia processo inflamatório crônico na derme, sem evidências de vasculite. A concordância entre $\mathrm{ACL}$ e AL não é de $100 \%$. Nem todos os pacientes com Sneddon apresentam os Apls. Parece que são mais freqüentemente observados nos pacientes com presença de dimência associada (múltiplos infartos) ${ }^{8}$.

A fisiopatologia dos infartos ainda é controversa, mas foi observado a presença de trombos fibrino-plaquetários em vasos pequenos, na ausência de lesões vasculares associadas, sugerindo uma possível trombose intravascular in situ. Por outro lado, é freqüente o achado de lesões cardíacas, incluindo degeneração da válvula mitral e endocardite asséptica nos pacientes com Apls, as quais também podem estar envolvidas na sua fisiopatologia. $O$ achado de vasculite é incomum. A trombose pode ocorrer tanto em pequenas como em grandes artérias e veias da circulação cerebral anterior e posterior. Foram ocasionalmente descritos infartos lacunares, lesões na substância branca e infartos extensos, mas a apresentação mais freqüente é de pequenos infartos localizados na região cortical e subcortical adjacente ${ }^{7}$.

Considerando estes dados, o tratamento profilático consistiria em agentes antiplaquetários; em caso de falha terapêutica poderiam ser introduzidas drogas anticoagulantes. Na ausência de manifestações autoimunes, a terapia imunomodulatória, por exemplo com corticosteróides, não é apropriada, pelo menos como terapêutica inicial, a não ser que o tratamento com drogas anticoagulantes tenha falhado.

Outras opções teapêuticas: drogas imunossupressoras como a ciclofosfamida, plasmaferese e altas doses de imunoglobulinas IV tem sido estudadas ${ }^{7}$.

A prevalência dos Apls nos pacientes com AVC (considerando todos os grupos etários) é de cerca de 2 a $5 \%$ até $16 \%$ dependendo do teste utilizado e da idade dos pacientes (até $46 \%$ em pacientes jovens) ${ }^{6,7,8}$. Hess e cols. detectaram uma prevalência de $8.6 \%$ de ACLs em pacientes com AVCs ou EIT, comparada com uma taxa de $1,6 \%$ em pacientes do grupo controle $^{10}$. Estima-se que a frequência de recorrência de AVCs nestes pacientes seja cerca de 13 a $14 \%$ ao ano e a taxa de mortalidade, $10 \%$ ao ano ${ }^{13}$.

Estima-se que a incidência de trombose na população com Apls é de cerca de $30 \%$ sendo que eventos trombóticos cerebrovasculares são eventos importantes desta síndrome. Os pacientes acometidos geralmente são jovens que permanecem com sequelas importantes 4 .

A Trombose pode ocorrer tanto nos sistemas venosos, arteriais, assim como na microvasculatura, apesar de uma maior frequência das tromboses venosas Brey e col. descrevem antifosfolípides detectáveis em 21 dos 46 pacientes $(46 \%)$ com menos de 50 anos com AVC e episódio isquêmico transitório (EIT), comparados com somente 2 dos 26 pacientes ( $8 \%$ ) do grupo controle com doenças neurológicas não trombóticas ${ }^{2}$.

Estudos retrospectivos confirmam esta tendência de apresentação na idade jovem, na ausência de doenças do colágeno e uma predisposição a eventos trombóticos múltiplos e recorrentes (estudos de Kushner e cols, Levine e cols e Coull e cols ${ }^{6,7,12,13}$ ). Em um grande estudo multicêntrico retrospectivo (Antiphospholipid Antibodies in Stroke Study Group ') observou-se uma frequência duas a quatro vezes maior de ACLs em 248 pacientes não selecionados com AVC, quando comparada a outros grupos de controles hospitalares, sugerindo a importância da anticardiolipina como um fator de risco independente para a doença cerebrovascular.

\section{NOSSA EXPERIENCIA}

O grupo de Doenças Cerebrovasculares da Divisão de Clínica Neurológica do HCFMUSP, realizou um estudo com o intuito de analisar o papel dos anticorpos antifosfolípides na etiologia dos AVCIs na população de pacientes mais jovens atendida em nosso Serviço. Foram estudados 85 pacientes (49 mulheres e 36 homens) com a idade variando entre 14 a 45 anos, com seguimento ambulatorial de 4 a 28 meses (média de 15 meses) após o evento ictal. Baseado em dados clínicos como a presença de fatores de risco, assim como nos achados da investigação laboratorial, os pacientes foram classificados em 5 grupos conforme a etiologia mais provável:

1) aterotrombótica: diagnóstico angiográfico e/ou a presença de pelo menos 3 fatores de risco para arteriosclerose.

35 pacientes $=41,18 \%$

2) embólica (cardiogênica: valvopatias, arritmias, miocardiopatias, infarto recente)

21 pacientes $=24,71 \%$

$3)$ etiologia indeterminada 
14 pacientes $=16,47 \%$

4) grupo miscelânea: arterite, alterações hematológicas (por exemplo a síndrome primária de antifosfolípides), intoxicações por drogas, Moya-Moya.

13 pacientes $=15,30 \%$

5) traumática

2 pacientes $=2,34 \%$

A investigação laboratorial na pesquisa dos Apls incluiu: tempo de tromboplastina parcial ativada (TTPA), tempo de protrombina, VDRL, pesquisa de ACL (ELISA). A metodologia utilizada nos testes imunoenzimáticos para detecção da anticardiolipina seguiu a padronização descrita por Brey e cols ${ }^{2}$. Testes mais sensíveis para a deteç̧ão do AL foram realizados nos casos com prolongamento do TTPA ou quando havia uma suspeita clínica: tempo de protrombina com diluição $1 / 500$, tempo de tromboplastina parcial ativada (diluição a 50\%) e o tempo de recalcificação de plasma ativado com caulim (KCT Exner test). Todos os exames foram repetidos dois meses após o quadro ictal para evitar falsos positivos.

Destes pacientes, somente 10 pacientes $(11,8 \%)$ apresentavam testes positivos para pelo menos um dos Apls (houve concomitância de ambos Apls testados, em apenas três pacientes; quatro deles apresentavam positividade somente para o AL e três, apresentavam ACL:Igm e/ou IgG. Não foi pesquisada a presença de $\operatorname{IgA}$ ). A investigação clínica e laboratorial exclui a associação de doenças autoimunes assim como a presença dé infecções sistêmicas nestes pacientes. Seis deles apresentavam características clínicas da síndrome primária de Apls: lesões valvulares de câmera esquerda (4), aborto (4), trombose arterial: AVCI (6), trombose venosa profunda (1), Livedo retucularis confirmado por biópsia (3). Não foi observado a presença de trombocitopenia ou alterações visuais nestes pacientes. Três destes pacientes apresentavam a síndrome de Sneddon (sendo que duas delas haviam apresentado aborto). Nos outros quatro pacientes foi difícil estabelecer uma correlação entre a presença dos Apls e os AVCs pois apresentavam alterações angiográficas compatíveis com doença aterotrombótica e/ou outros fatores de risco associados: HAS, hipercolesterolemia, tabagismo e uso de contraceptivo oral.

Em relação aos achados angiográficos nos pacientes com suspeita de síndrome antifosfolípides foram observados: exame normal em quatro, oclusão de ramos arteriais distais (artéria cerebral média e posterior), em dois casos. Os demais casos evidenciaram sinais sugestivos de doença ateromatosa.

Em relação aos pacientes com provável síndrome dos anticorpos antifosfolípides, somente dois deles apresentavam histórias de eventos isquêmicos precedendo o episódio atual.

Os pacientes foram tratados inicialmente com aspirina. Um deles passou a apresentar episódios isquêmicos transitóros recorrentes e foi submetido a anticoagulação, com boa resposta terapêutica. Duas das pacientes com Sneddon, desnvolveram quadros demenciais a despeito do tratamento (inicialmente com aspirina e depois drogas imunossupressoras).

\begin{tabular}{|c|c|c|c|c|c|c|c|}
\hline & Idade & Sexo & $\begin{array}{l}\text { Quadro } \\
\text { Clínico }\end{array}$ & $A L$ & $\operatorname{Ig} M^{A}$ & $I g C$ & $V D R L$ \\
\hline 1 & 43 & $M$ & $\begin{array}{c}\mathrm{AVCI}+ \\
\text { TVP } \\
\end{array}$ & NEG & NEG & POS & NEG \\
\hline 2 & 38 & $\mathrm{~F}$ & AVCI & POS & NEG & NEG & NEG \\
\hline 3 & 35 & $\mathrm{~F}$ & $\begin{array}{l}\text { TVP+ } \\
\text { AVCI } \\
\end{array}$ & POS & POS & NEG & NEG \\
\hline 4 & 34 & $\mathrm{~F}$ & AVCI & POS & NEG & NEG & NEG \\
\hline 5 & 34 & $\mathrm{~F}$ & $\begin{array}{c}\text { ABORTO } \\
+ \text { AVCI } \\
\end{array}$ & POS & NEG & POS & NEG \\
\hline 6 & 33 & $\mathrm{~F}$ & $\begin{array}{c}\text { ABORTO } \\
+ \text { AVCI } \\
\end{array}$ & NEG & NEG & POS & NEG \\
\hline 7 & 22 & M & AVCI & POS & NEG & NEG & NEG \\
\hline 8 & 35 & $\mathrm{~F}$ & SNEDDON & POS & NEG & POS & NEG \\
\hline 9 & 25 & $\mathrm{~F}$ & SNEDDON & POS & NEG & NEG & NEG \\
\hline 10 & 20 & $\mathrm{~F}$ & SNEDDON & NEG & NEG & POS & NEG \\
\hline
\end{tabular}

$\mathrm{AL}=$ Anticoagulante lúpico $\mathrm{ACL}=$ Anticardiolipina $\mathrm{VDRL}=$ Reações sorológicas: Lue TVP $=$ Trombose venosa profunda $\quad$ AVCI $=$ Acidente vascular cerebral isquêmico Nos pacientes 1, 2, 4 e 7 nāo foi possível inferir uma correlação entre a presença dos Apls e os AVCIs pois apresentavam outros fatores de risco assim como achados angiográficos compatfvejs com doença ateromatosa.

No presente estudo não foi possível estabelecer uma correlação entre a presença dos Apls e a gravidade da doença ou com a presença de demência. Nós pretendemos aprofundar este estudo não só aumentando nossa casuística como também complementando a pesquisa do anticoagulante lúpico com testes mais sensíveis como o teste do veneno da víbora Russel.

Apesar do papel ainda controverso dos Apls na fisiopatologia dos infartos cerebrais, a sua pesquisa, em nossa opinião, deve fazer parte da investigação clínica da etiologia dos AVCIs principalmente nos pacientes mais jovens.

\section{Agradecimentos}

Os autores agradecem ao setor de Coagulação da Fundação Hemocentro do Hospital da Clínicas da FMUSP Disciplina de Hematologia, pela realização dos testes de pesquisa para o anticoagulante lúpico.

\section{SUMMARY}

Lupos anticoagulant and anticardiolipin are members of a heterogeneous group of antibodies called antipholipids with varying specificities for phospholipids. They have been associated with variable thromboembolic syndrome including recurrent venous and arterial thrombosis and fetal loss. Thrombotic events may affect every organ, including the brain circulation. Stroke seems to occur in nearly $20 \%$ of the patients. Retrospective studies suggest a tendency to presentation at a young age and the frequent absence of the clinical and laboratory evidence of collagen vascular disease. In our study, Apls were detected in $11,8 \%$ of the young patients with diagnosis of 
stroke. Despite the low frequence of Apls, its research must be included in the laboratory investigation for stroke mainly in the young population.

\section{Bibliografia}

1 Apass. Clinical, Radiological and pathological aspects of cerebro vascular disease associated with Antiphospholipids antibodies. Stroke, 1993, vol 24, 12(suppl I), 1120-1123.

2 Broy RL, Hart RG, Sherman DG, Tegeler CH. Antiphospholipid antibodies and cerebral ischemia in yong people. Neurology, 1990, 40, 1190-1196.

3 Briley DP, Coull BM, Goodnigth SH Jr. Neurological disease associated with antiphospholipid antibodies. Ann Neurol, 1989, 25, 221-227.

4 Canoso RT. Antiphospholipid antibodies. Basic mechanisms, clinical features and animal models. Stroke, 1993, vol 24, 12(suppl I), 11241125.

5 Conley CL, Hartmann RC. A haemorrhagic disorder cuased by circulation anticoagulant in patients with disseminated lupus erythematosus. J Clin Invest. 1952, 31, 621-3.
6 Coull BM, Bourdette DN, Goodnight SH, Briley DP, Hart R. Multiple cerebarl infarctions and dementia associated with anticardiolipin antbodies. Stroke. 1987; 18:1107-12.

7 Coull BM, Levine SR, Brey RL. The role of antiphospholipid antibodies in stroke. Neurol Clin, 1992, 12, 125-143.

8 Greaves M. Coagulation abnormalities and cerebral infarction. J Neurol Neurosurg Psychlatry, 1993, 56, 433-439.

9 Hart RG, Kanter MC. Hematologic disorders and ischemic stroke: a selective review. Stroke, 1990, 21, 1111-1121.

10 Hess DC. Stroke associated with antiphospholipid antibodies. Stroke, 1992, 23(suppll), 1-23-1-28.

11 Kilpatrick TJ, Matkovic Z, Davis SM. McGranth CM, Dauer RJ. Hematological abnormalities occur in both cortical and lacunar infarction. Stroke, 1993, 24, 12, 1945-1950.

12 Kuschner M, Simonan N. Lupus anticoagulant, anticardiolipin antibodies and cerebral ischaemia. Stroke, 1989, 20:225-9.

13 Levine SR, Welch KMA. The spectrum of neurologic disease assiciated with antiphospholipid antibodies. Arch Neurol, 1987, 44, 876-883.

14 Tinone G, Yamamoto FI, Comerlatti LR, Scaff M. Antiphospholipid antibodies (Apls) and ischemic stroke in the yong. Can J Neurol Sci, 1993, suppl4, S245.

15 Verstrate $M$, Vermylen J. Testes hematológicos $\theta$ trombose. In Trombose, traduzido e atualizado por Fujimura AYH ecols, Săo Paulo: Savier, 1989, 47-59. 